Christian Braendle • Neal Hockley • Thomas Brevig •

Alexander W. Shingleton • Laurent Keller

\title{
Size-correlated division of labour and spatial distribution of workers in the driver ant, Dorylus molestus
}

Received: 19 February 2003 / Accepted: 10 April 2003 / Published online: 24 May 2003

(C) Springer-Verlag 2003

\begin{abstract}
Driver ants (Dorylus spp.) show a high degree of worker polymorphism. Previous reports suggest that large Dorylus workers are specialised for defensive tasks. In this study, we first quantitatively tested whether there is a size-correlated division of defensive labour among workers. Second, we determined whether the spatial distribution of workers outside the nest can be predicted based on such size-specific differences in task allocation. We show that the division of defensive behaviour among different-sized workers is not strict. However, there is a significant correlation between worker size and the tendency to carry out defensive tasks. First, workers of larger size were more likely than smaller workers to participate in colony defence. Second, larger workers were more frequent near the nest containing the reproducing individuals and the brood. Finally, large workers were more common in open sections of the trail than in
\end{abstract}

C. Braendle $(\bullet) \cdot$ N. Hockley

Department of Zoology,

University of Cambridge,

Cambridge, UK

e-mail: braendle@princeton.edu

Tel.: +1-609-2585587

Fax: +1-609-2581712

T. Brevig

Department of Biology,

University of Oslo,

Oslo, Norway

A. W. Shingleton

Department of Ecology and Evolutionary Biology,

Princeton University,

Princeton, NJ, 08544, USA

L. Keller

Institute of Ecology,

University of Lausanne,

Lausanne, Switzerland

Present address:

C. Braendle, Department of Ecology and Evolutionary Biology,

Princeton University,

Princeton, NJ, 08544, USA covered sections, which are likely to be less exposed to predators.

\section{Introduction}

Worker polymorphism of continuous or discrete nature occurs in approximately $20 \%$ of ant genera (Oster and Wilson 1978). The presence of alternative morphologies in the worker caste is usually interpreted as an adaptive phenomenon reflecting the physical fine-tuning of different worker types to their specialised task functions. Past research has analysed the significance of worker polymorphism mainly by asking how worker castes or worker size variation is matched to the requirements of specific tasks, with a possible increase in colony efficiency. By contrast, relatively little research (e.g. Cerdá and Retana 1997) has focused on the spatial distribution of polymorphic workers, and how this distribution relates to the task repertoire of workers.

Here we address aspects of this question by studying the trail systems of the African driver ant, Dorylus molestus. Dorylus species are group predators and build extensive trail systems when swarm raiding (Gotwald 1995). Foraging trails are variable in space: some sections are built underground, whereas others are built on the ground surface, where they may be partly or fully covered with soil particles (Gotwald 1995). A number of visually hunting predators, such as primates, are known to feed on worker trails of Dorylus (Gotwald 1995). These predators may locate open trails because the dense aggregation of dark-coloured workers strongly contrasts with the ground surface in most of the encountered habitats. Open trails generally contain a large number of workers standing along the trail margins that assume a guard posture by elevating their heads and holding their mandibles wide open (Gotwald 1995).

Dorylus workers vary along a size continuum and show size-dependent morphological differences (Raignier and van Boven 1955). Large workers differ from small workers by possessing falcate, sharply pointed mandibles 
which appear to be well suited for piercing skin or cuticle, but less so for other tasks. Hence, these workers seem to be morphologically well-suited to assume a defensive function and have usually been termed soldiers (Gotwald 1995). However, no studies have quantitatively assessed whether large workers are preferentially involved in defensive tasks.

The aim of this study was first to test whether there is a size-based division of labour among workers, and second to determine whether the spatial distribution of workers of different sizes can be predicted based on size-specific differences in task performance. Since large workers are presumed to be specialists for defence, we predict that they will be more likely than smaller workers to participate in colony defence and should be more common in those trail sections where an increased need of defence is expected. Specifically, we tested the following three predictions.

1. Large workers are more likely to defend the colony compared with small workers.

- We tested this by disturbing foraging trails and comparing the size of workers responding to the disturbance to a random sample of workers taken from a similar section of the foraging trail.

2. Large workers (defenders) are more common in trails close to the nest than away from the nest.

- An increased defence investment can be expected at trail sections close to an important resource of the colony. A predator attacking the nesting site will destroy brood and possibly kill the current and future reproductive individuals. In contrast, an attack on a trail far away from the nest is likely to have relatively little influence on colony fitness. Predation by vertebrates that feed at the nesting site, either on adult workers or on the brood of driver ants, has been reported in several studies (references in Gotwald 1995; Humle and Matsuzawa 2002). Consequently, increased protection of the nest may be established by increased allocation of defenders in trail sections close to the nesting site. We tested this prediction by comparing worker size between samples taken from open trails close to and away from the nest.

\section{Large workers (defenders) are more frequent in open} trail sections than in covered trail sections.

- Since open trails are more easily detectable than underground trails and because predators are known to feed on workers on open trails, we predict that larger workers are more common in such trail sections compared with sections which are covered by soil particles or which are built underground.

\section{Methods}

Study site and experimental design

The study was conducted in the surroundings of Amani, a village in the East Usambara Mountains, Tanzania. During the late dry season (15-29 September 1998) we collected worker samples from nine colonies, separated from each other by between 1 and $20 \mathrm{~km}$. We collected all samples between 1000 hours and 1700 hours in daylight. Once we had located trails of workers, we identified the nest location by following the principal trail in the direction workers were carrying their prey. From each colony we collected the following four samples:

1. Sample of workers randomly collected from an open trail section near the nest (RON)

2. Sample of workers randomly collected from a covered trail near the nest $(\mathrm{RCN})$

3. Sample of defending workers collected from an open trail section near the nest (DON)

4. Sample of defending workers collected from an open trail section far from the nest (DOF).

The samples (RON, RCN, DON) were collected from a section of the principal trail adjacent to the nesting area, approximately 2 $10 \mathrm{~m}$ away from the nest, depending on trail and habitat structure. The RON samples were taken from an open trail section by randomly collecting workers on the trail. The RCN samples were collected from a trail section completely covered with soil particles. We used a small shovel to remove a complete, approximately 10 $15 \mathrm{~cm}$ long section of the trail and collected all workers from this section. To standardise the collection of defending workers in the DON samples, we dipped a nylon string $(30 \mathrm{~cm}$ long and $0.5 \mathrm{~cm}$ in diameter) into an open trail section. Workers reacted to this disturbance by climbing up the string, often biting into the fibres of the string. Dorylus workers immediately respond to any source of disturbance and will attack it (e.g. Gotwald 1995). As the dipping of the string elicited an obvious defensive response of the workers, we considered this stimulus as appropriate for the sampling of defending individuals. After dipping the string for $15 \mathrm{~s}$ into the trail, all ants attached to the string were collected. This was done three times, each time using a new piece of string to obtain a large enough sample of workers. The fourth sample (DOF) was collected in the same manner as DON samples, but at a distance of 30-50 m further away from the nest. For each colony, the four samples were collected within a maximum of $15 \mathrm{~min}$. First it was decided at random whether to collect the sample(s) close to the nest or away from the nest. When sampling nearby the nesting site, it was again randomly decided in which order to collect the three samples. Samples from the nesting area were collected within less than $5 \mathrm{~min}$ to minimise potential effects of the sampling on later sampling events.

\section{Statistical analyses}

We collected a total of 4,912 workers. The number of individuals collected sometimes differed considerably between samples (mean \pm SE 140.3 \pm 23.7 , range 5-345). Two samples taken from covered trail sections were very small $(n=5$ and $n=13)$ whereas all other samples contained 37 or more workers.

To obtain an estimate of body size we measured maximum head width, which is a good correlate of total body length (Spearman rank correlation, $r=0.99, n=250, P=0.00001$; random sample taken from a single colony).

To test whether larger workers were involved in defence (prediction 1) we compared the head width of defending workers to the head width of randomly collected workers from an open trail near to the nest (DON vs RON). To test whether the defending workers were larger close to the nest rather than away from the nest (prediction 2) we compared the head width of defending workers from open trails near and far from the nest (DON vs DOF). To test 
whether larger workers were more frequently found in open rather than covered trails (prediction 3) we compared the head width of randomly collected workers from open and closed trails near to the nest (RON vs RCN). The head widths were compared using twoway mixed-effect ANOVAs using Type III sum-of-squares, treating 'sample type' (e.g. DON, RON, etc) as a fixed factor and 'colony' $(n=9)$ as a random one. To satisfy assumptions of homogeneity of variance and normality of error, the data were log-transformed prior to analysis. Because all three tests used combinations of data from the same experiment, and to avoid inflation of Type I error, we applied a Dunn-Sidák correction to the significance level, reducing it to $1.7 \%$ (Sokal and Rohlf 1995).

In a second analysis, we divided workers into six arbitrary size classes (1) $0.4-0.8 \mathrm{~mm}$, (2) $0.9-1.3 \mathrm{~mm}$, (3) $1.4-1.8 \mathrm{~mm}$, (4) 1.9 $2.3 \mathrm{~mm}$, (5) $2.4-2.8 \mathrm{~mm}$ and (6) $>2.8 \mathrm{~mm}$. For each size class, we qualitatively compared the frequency of workers between samples.

\section{Results}

Workers varied greatly in size (head width range: 0.4 $3.7 \mathrm{~mm})$. Size class 2 was the most frequent (44-66\% of all workers) in all four samples collected, regardless of colony of origin. Figure 1 shows an example illustrating the frequencies of worker sizes in the four different samples collected from one of the colonies.

The mean size of workers varied significantly between all samples (see below). In all cases the interaction between the factors 'colony' (1-9) and 'sample type' (RCN, RON, DON, DOF) was also significant, indicating
Fig. 1 Example of the size frequency distribution of workers in the four different samples taken from a single colony. $R C N$ Random sample collected from a covered trail near the nest (mean $\pm \mathrm{SE}=1.16 \pm 0.03$, $n=282$ ). RON Random sample collected from an open trail near the nest (mean \pm $\mathrm{SE}=1.41 \pm 0.04, n=207)$. DON Sample of defending individuals from an open trail near the nest (mean $\pm \mathrm{SE}=1.50 \pm 0.06$, $n=129)$. DOF Sample of defending individuals from an open trail away from the nest $($ mean $\pm \mathrm{SE}=1.34 \pm 0.06, n=80)$

\section{Number of individuals}
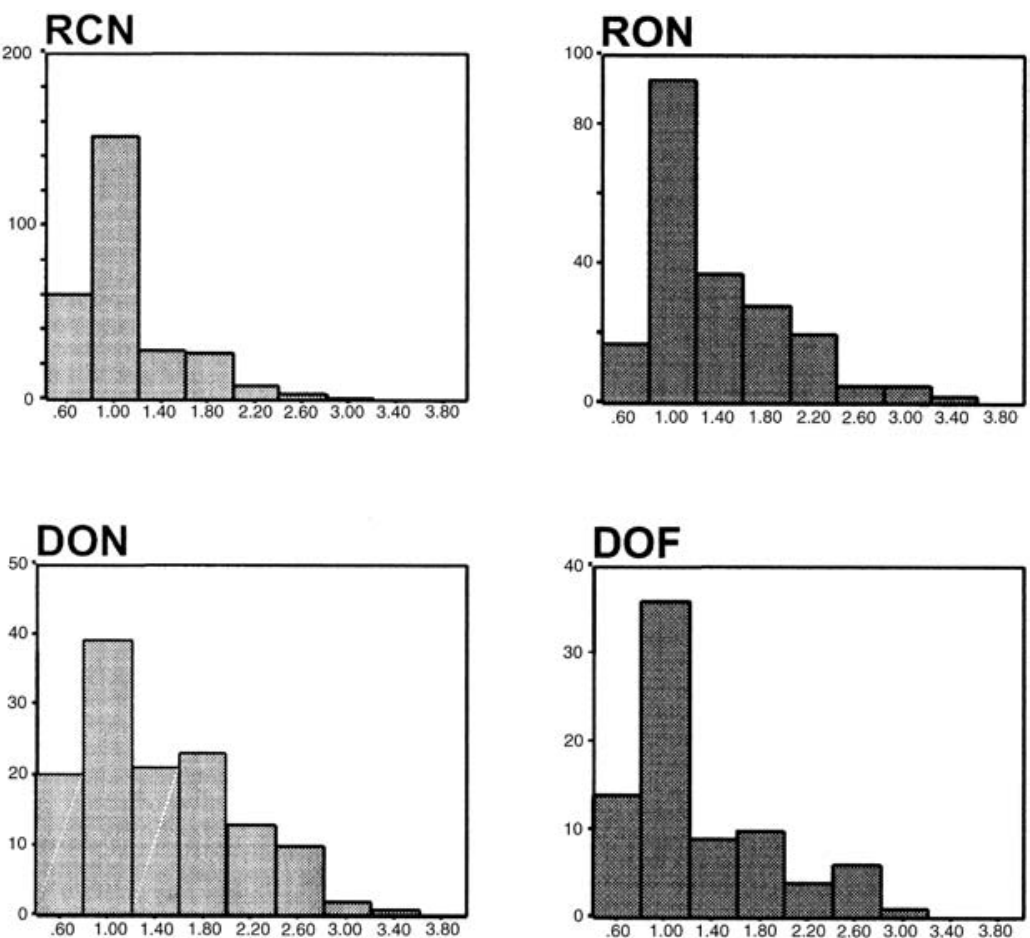

\section{Maximum Head Width (mm)}

Table 1 Test of predictions 1-3: worker size differences between samples

\begin{tabular}{|c|c|c|c|c|c|}
\hline Comparison & $\begin{array}{l}\text { Mean size } \pm \text { SE [median] } \\
\text { (Sample type) }\end{array}$ & $\begin{array}{l}\text { Mean size } \pm \text { SE [median] } \\
\text { (Sample type) }\end{array}$ & $\begin{array}{l}\text { Main effect } \\
\text { sample type }\end{array}$ & $\begin{array}{l}\text { Main } \\
\text { effect colony }\end{array}$ & $\begin{array}{l}\text { Interaction sample } \\
\text { type } \times \text { colony }\end{array}$ \\
\hline $\begin{array}{l}\text { DON-RON } \\
\text { (Test of prediction 1) }\end{array}$ & $\begin{array}{l}1.48 \pm 0.02 \\
{[1.30]} \\
(\mathrm{DON})\end{array}$ & $\begin{array}{l}1.27 \pm 0.01 \\
{[1.10]} \\
(\mathrm{RON})\end{array}$ & $\begin{array}{l}F_{1,7.1}=16.74 \\
P=0.005\end{array}$ & $\begin{array}{l}F_{8,6.87}=1.885 \\
P=0.211\end{array}$ & $\begin{array}{l}F_{7,2768}=7.61 \\
P=0.0001\end{array}$ \\
\hline $\begin{array}{l}\text { DON-DOF } \\
\text { (Test of prediction 2) }\end{array}$ & $\begin{array}{l}1.48 \pm 0.02 \\
{[1.30]} \\
(\mathrm{DON})\end{array}$ & $\begin{array}{l}1.32 \pm 0.01 \\
{[1.20]} \\
(\mathrm{DOF})\end{array}$ & $\begin{array}{l}F_{1,8.399}=8.61 \\
P=0.018\end{array}$ & $\begin{array}{l}F_{8,8}=1.03 \\
P=0.484\end{array}$ & $\begin{array}{l}F_{8,2335}=6.43 \\
P=0.0001\end{array}$ \\
\hline $\begin{array}{l}\text { RON-RCN } \\
\text { (Test of prediction 3) }\end{array}$ & $\begin{array}{l}1.27 \pm 0.01 \\
{[1.10]} \\
(\mathrm{RON})\end{array}$ & $\begin{array}{l}1.08 \pm 0.01 \\
{[1.00]} \\
(\mathrm{RCN})\end{array}$ & $\begin{array}{l}F_{1,14.57}=16.25 \\
P=0.001\end{array}$ & $\begin{array}{l}F_{8,6.00}=6.53 \\
P=0.011\end{array}$ & $\begin{array}{l}F_{7,2542}=3.95 \\
P=0.0001\end{array}$ \\
\hline
\end{tabular}

RCN: random sample collected from a covered trail near to the nest RON: random sample collected from an open trail near to the nest

DON: sample of defending individuals from an open trail near to the nest

DOF: sample of defending individuals from an open trail far from the nest 

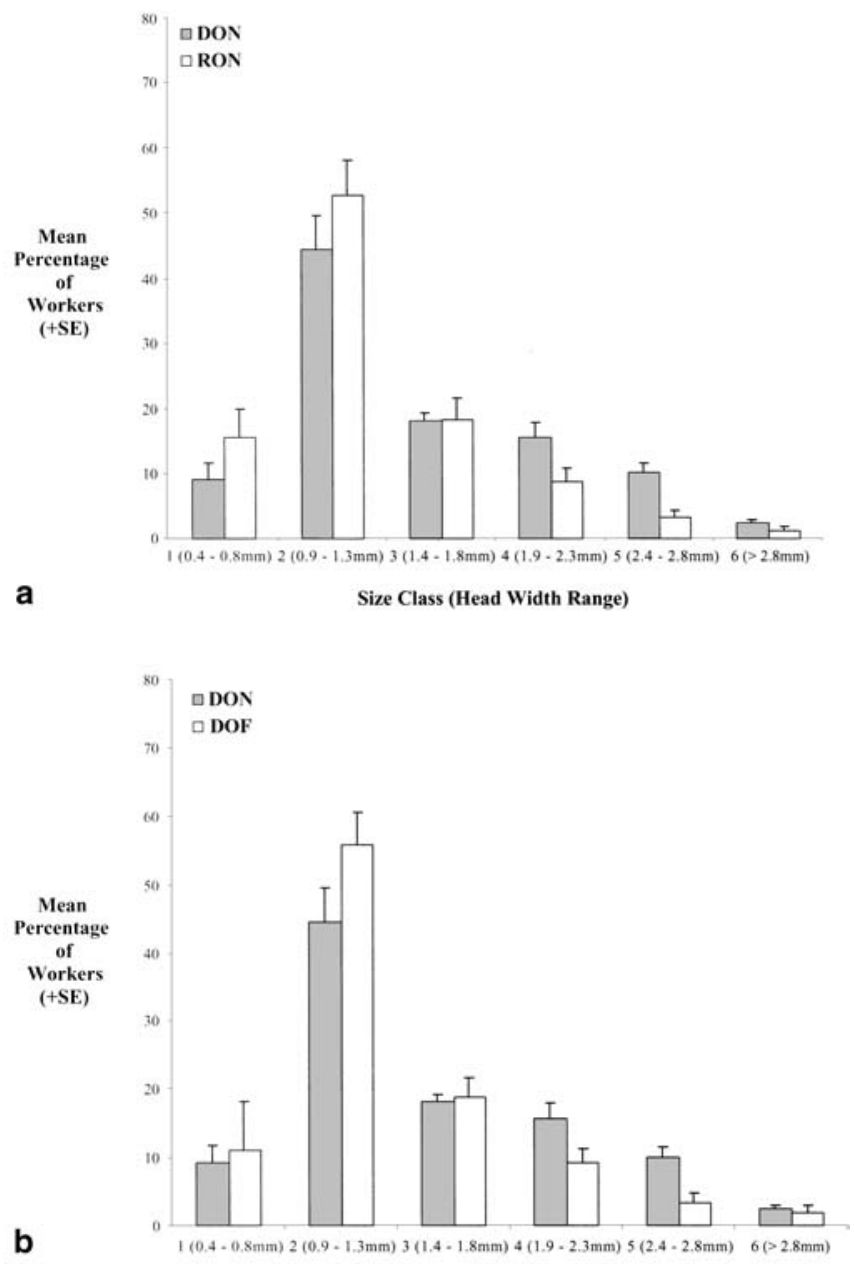

Size Class (Head Width Range)

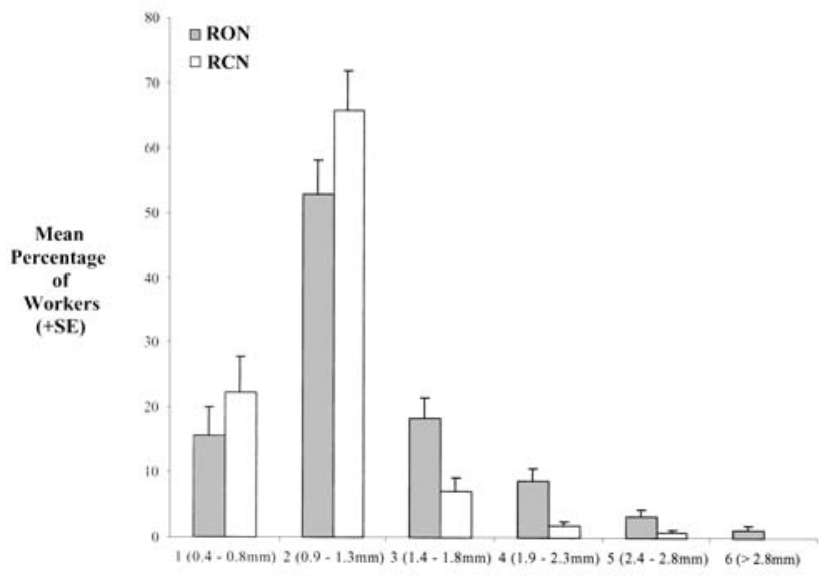

C

Fig. 2a-c Sample differences in the frequencies of workers in each of the six size classes. For each size class, the mean percentages of workers in the two samples are shown. a Comparisons between samples DON and RON (test of prediction 1); b comparisons between samples DON and DOF (test of prediction 2); c comparisons between samples RON and RCN (test of prediction 3) that the magnitude of the difference between the compared samples varied among colonies (Table 1).

1. Large workers are more likely to defend the colony compared with small workers.

- Workers that responded to the disturbance at an open trail section (DON) were significantly larger than workers collected at random from an undisturbed open trail section (RON) (Table 1). Worker size frequencies differed greatly in all but one size class. Workers of size classes 4-6 were more frequent in samples from disturbed trail parts (DON), whereas workers of size classes 1 and 2 were more frequent in samples from undisturbed trail parts (RON) (Fig. 2a).

2. Large workers (defenders) are more common in trails close to the nest than away from the nest.

- Workers responding to the disturbance close to the nest (DON) were significantly larger than workers responding to the disturbance far from the nest (DOF) (Table 1). The greatest differences existed in size classes 4 and 5 with a much higher frequency of these workers close to the nest than further away. On the other hand, class 2 workers were more common among defending workers collected away from the nest (Fig. 2b).

3. Large workers (defenders) are more frequent in open trail sections than in covered sections.

- Workers collected from open trail sections (DON) were significantly larger than workers collected from covered trail sections (RCN) (Table 1). Workers of size classes 3-6 were all more frequent in open trail sections. By contrast, small workers from (classes 1 and 2) tended to be more frequent in covered trail sections (Fig. 2c).

\section{Discussion}

Our data show that worker size was correlated with the tendency to defend. Predominantly, workers of class 4-6 performed colony defence; however, smaller workers also participated to some extent in colony defence. Therefore, although there is a size-correlated division of labour, this division is not strict. A similar pattern has been found for another task (prey retrieval) in D. molestus (Gotwald 1974), and overlapping division of labour in the same or other tasks has been found in other Dorylus species (see Raignier and van Boven 1955).

The spatial distribution of workers varied according to body size. First, we confirmed the prediction that the size of defending workers is greater near the nest than further away. Workers of size classes 4 and 5 were more frequent in samples collected close to the nest, whereas workers belonging to size classes 1 and 2 were more frequent in samples collected away from the nest. This result may be 
explained by an increased allocation of larger workers close to nest to provide an increased protection against potential nest predators. However, since we only collected workers responding to a disturbance close to the nest and away from the nest it is also possible that larger workers are more likely to defend when close to the nest then when further away. In any case, the increase of larger workers participating in defence reflects an increased defensive ability of the colony close to the nest.

We found that the average worker size is greater in open trails. In particular, workers of size classes 3-6 were more frequent in open trails than in covered trails. The increased allocation of larger workers in open trails could be related to an increased propensity of these workers to carry out defensive tasks or a higher frequency of these workers in open trails. Since open trails are more visible and accessible to predators, an increased defensive investment in such trails may be advantageous. In addition, or alternatively, factors such as differences in desiccation resistance may contribute to a differential distribution of different-sized workers among open and covered trails.

Large Dorylus workers have been termed soldiers, based on morphological and behavioural observations. We quantitatively demonstrate that large workers are more likely to carry out defensive behaviour than smaller workers. Larger workers are more common near the nest and in open trail sections, which seem to be preferred targets of predator attacks. This could indicate that the size-correlated division of labour and spatial distribution of workers may be adaptive in this driver ant. However, further manipulative experiments are required to confirm this interpretation of our results.

Acknowledgements This study was conducted during a Darwin Course in Tropical Biology organised by the Tropical Biology Association (TBA). We thank the TBA, in particular Rosie Trevelyan, for their support. William Gotwald, Jr., kindly identified the ant specimens. We thank Thomas Flatt for helpful comments on earlier versions of the manuscript. C.B. was funded by the Swiss Study Foundation, the Olga and Joseph-Tomscik Foundation, and the British Ecological Society (BES). T.B. was supported by funds from the University of Oslo via Nils Christian Stenseth, and the BES. L.K. was funded by grants from the Swiss NSF.

\section{References}

Cerdá X, Retana J (1997) Links between worker polymorphism and thermal biology in a thermophilic ant species. Oikos 78:467474

Gotwald WH Jr (1974) Predatory behaviour and food preferences of driver ants in selected African habitats. Ann Entomol Soc Am 67:877-886

Gotwald WH Jr (1995) Army ants: the biology of social predation. Cornell University Press, Ithaca, N.Y.

Humle T, Matsuzawa T (2002) Ant-dipping among the chimpanzees of Bossou, Guinea, and some comparisons with other sites. Am J Primatol 58:133-148

Oster GF, Wilson EO (1978) Caste and ecology in the social insects. Princeton University Press, Princeton, N.J.

Raignier A, Boven JKA van (1955) Etude taxonomique, biologique et biometrique des Dorylus du sous-genre Anomma (Hymenoptera Formicidae). Ann Mus R Congo Belge 2:1-359

Sokal RF, Rohlf FJ (1995) Biometry. Freeman, New York 